\title{
Application of a Domino Intramolecular Enyne Metathesis/Cross Metathesis Reaction to the Total Synthesis of 8-epi-Xanthatin
}

\author{
David A. Kummer, Jehrod B. Brenneman, and Stephen F. Martin* \\ Department of Chemistry and Biochemistry, The University of Texas, Austin, Texas \\ 78712, USA \\ sfmartin@mail.utexas.edu
}

Supporting Information 

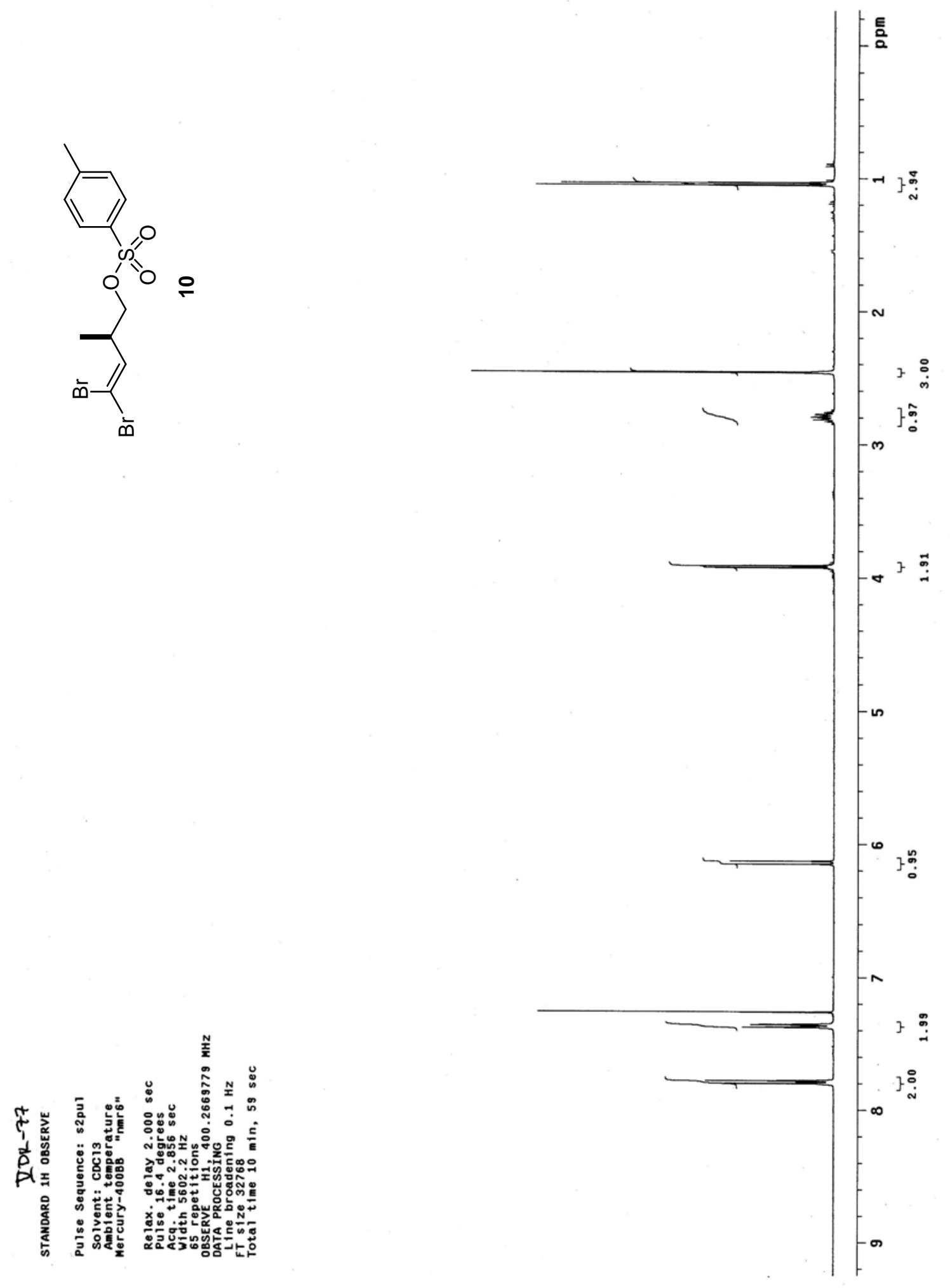


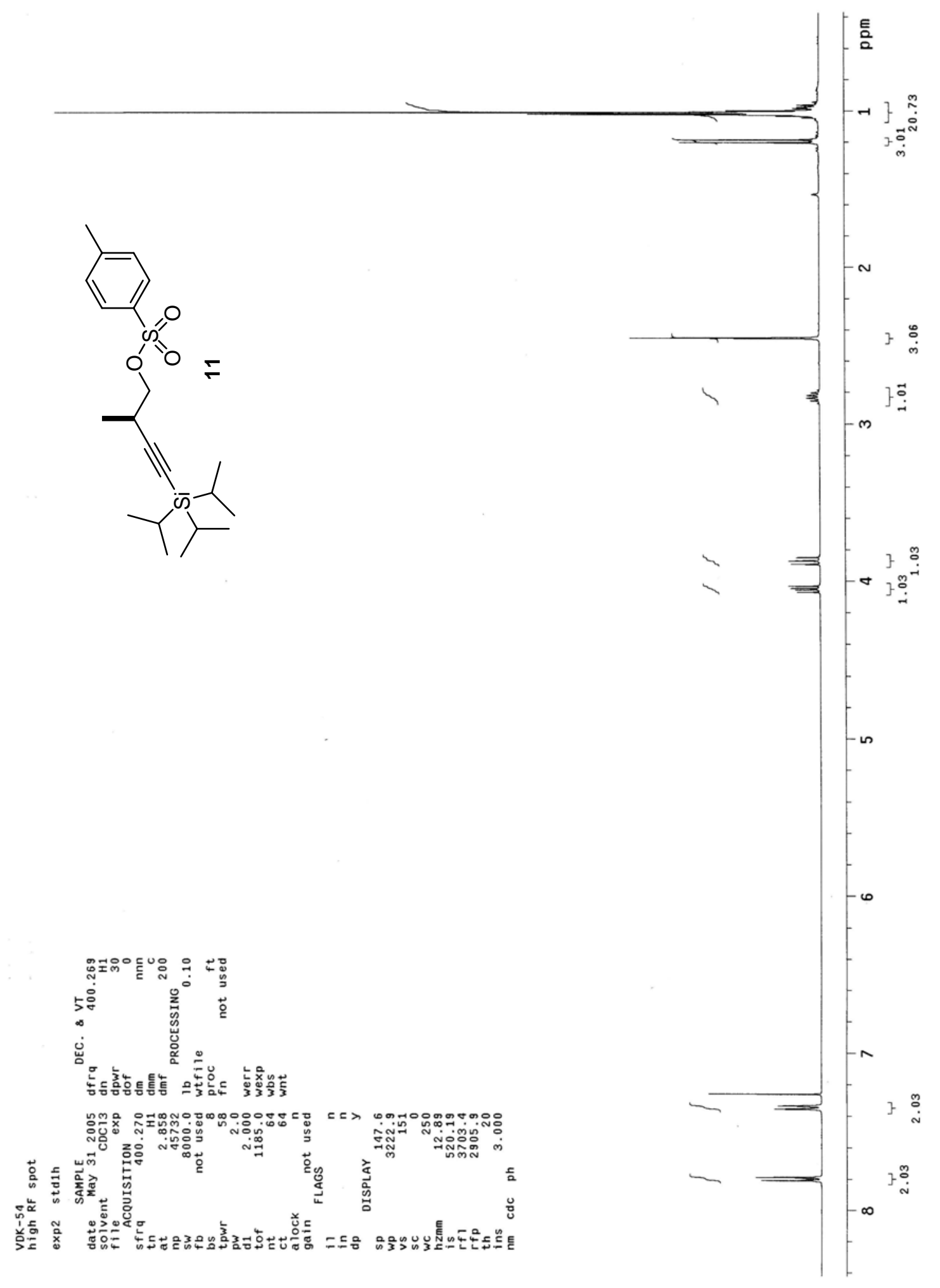




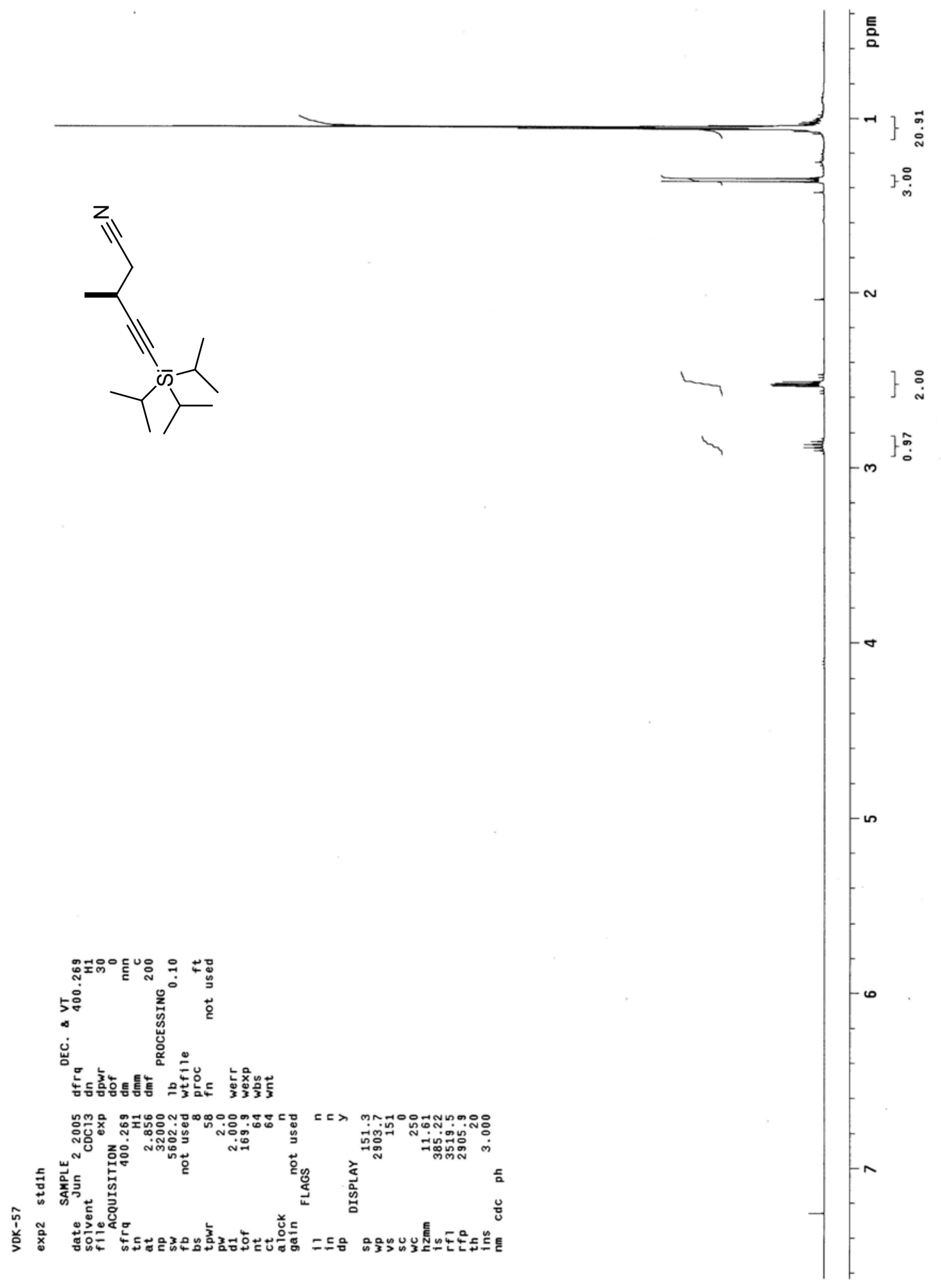


3

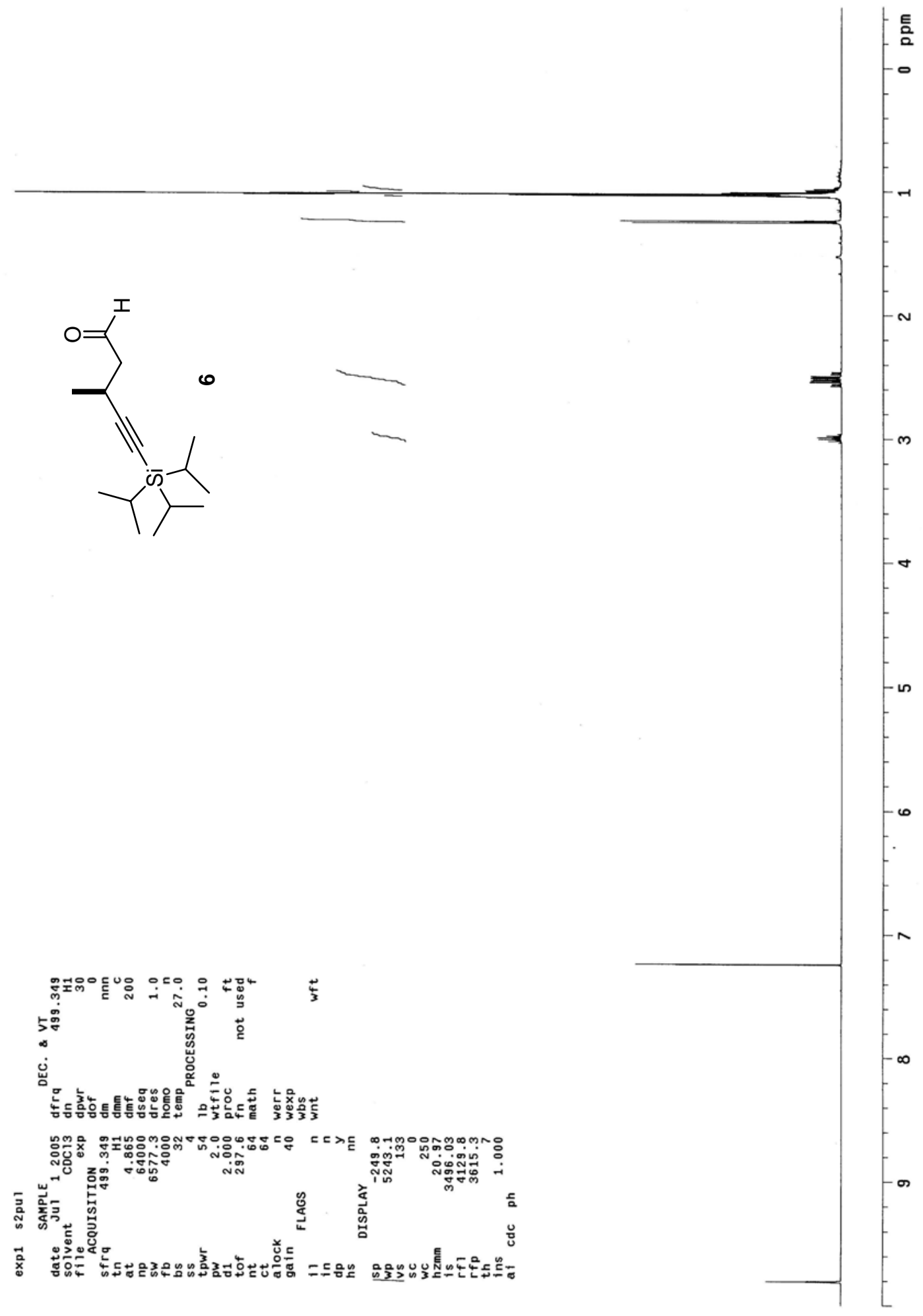




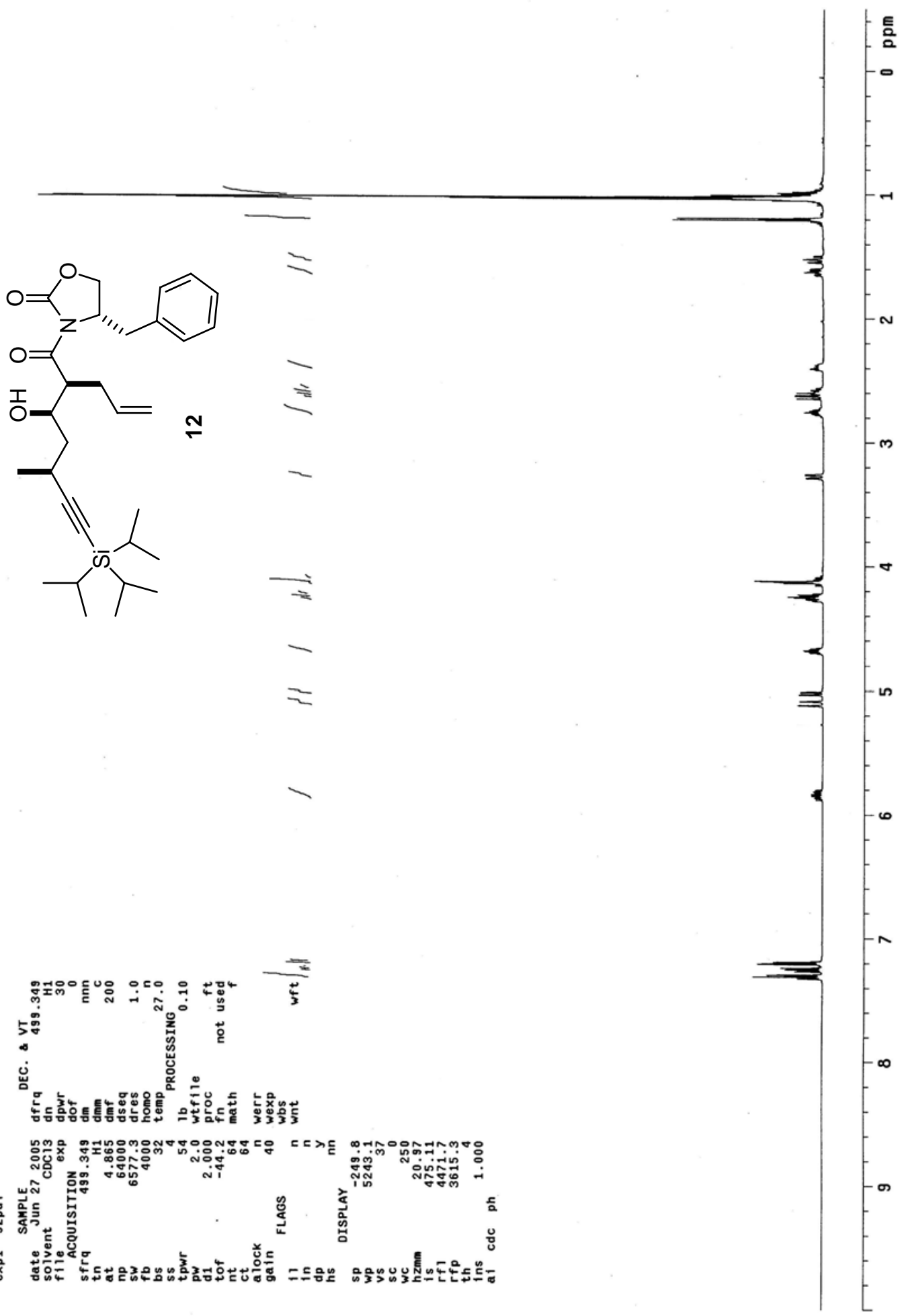




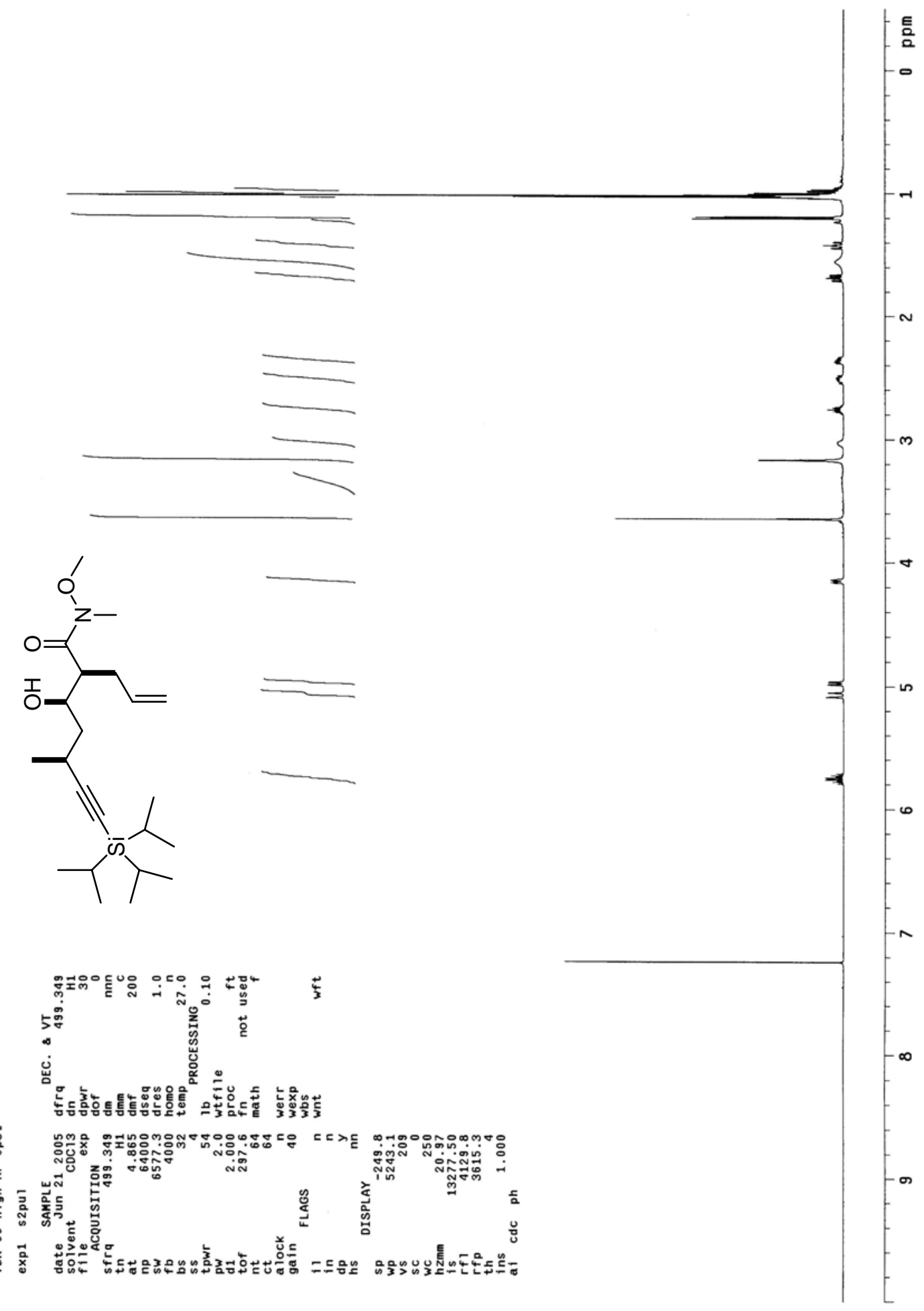




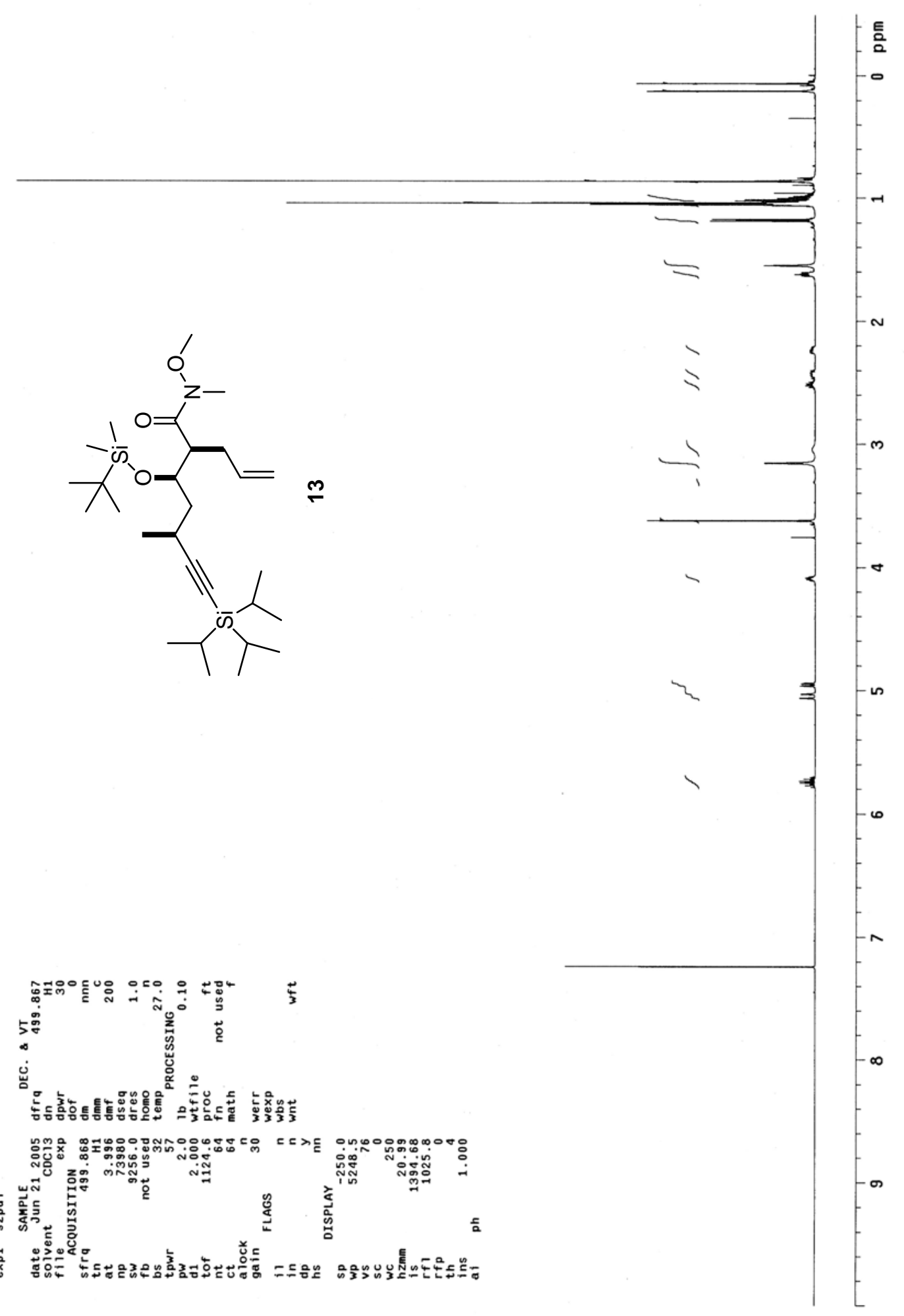


3

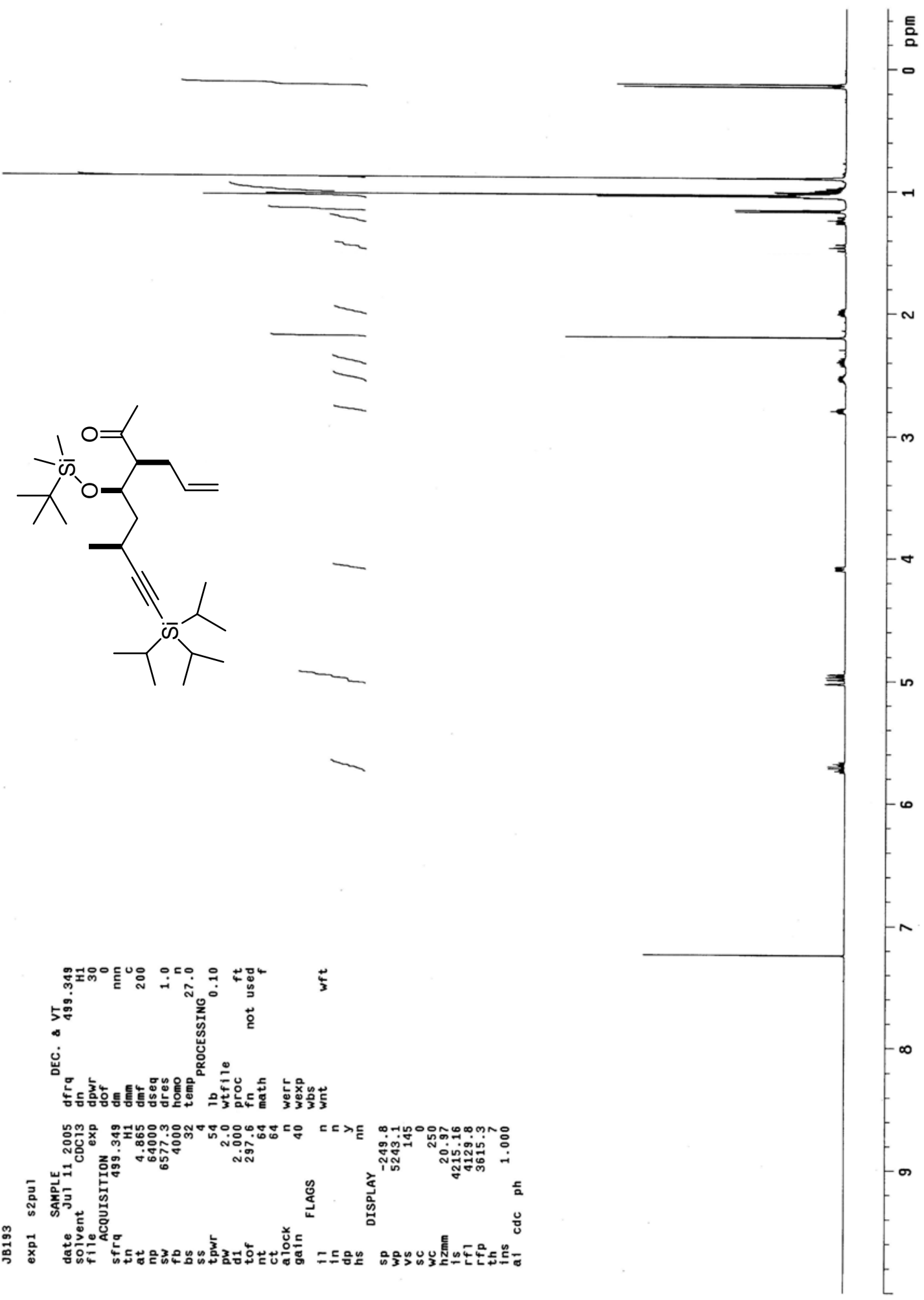




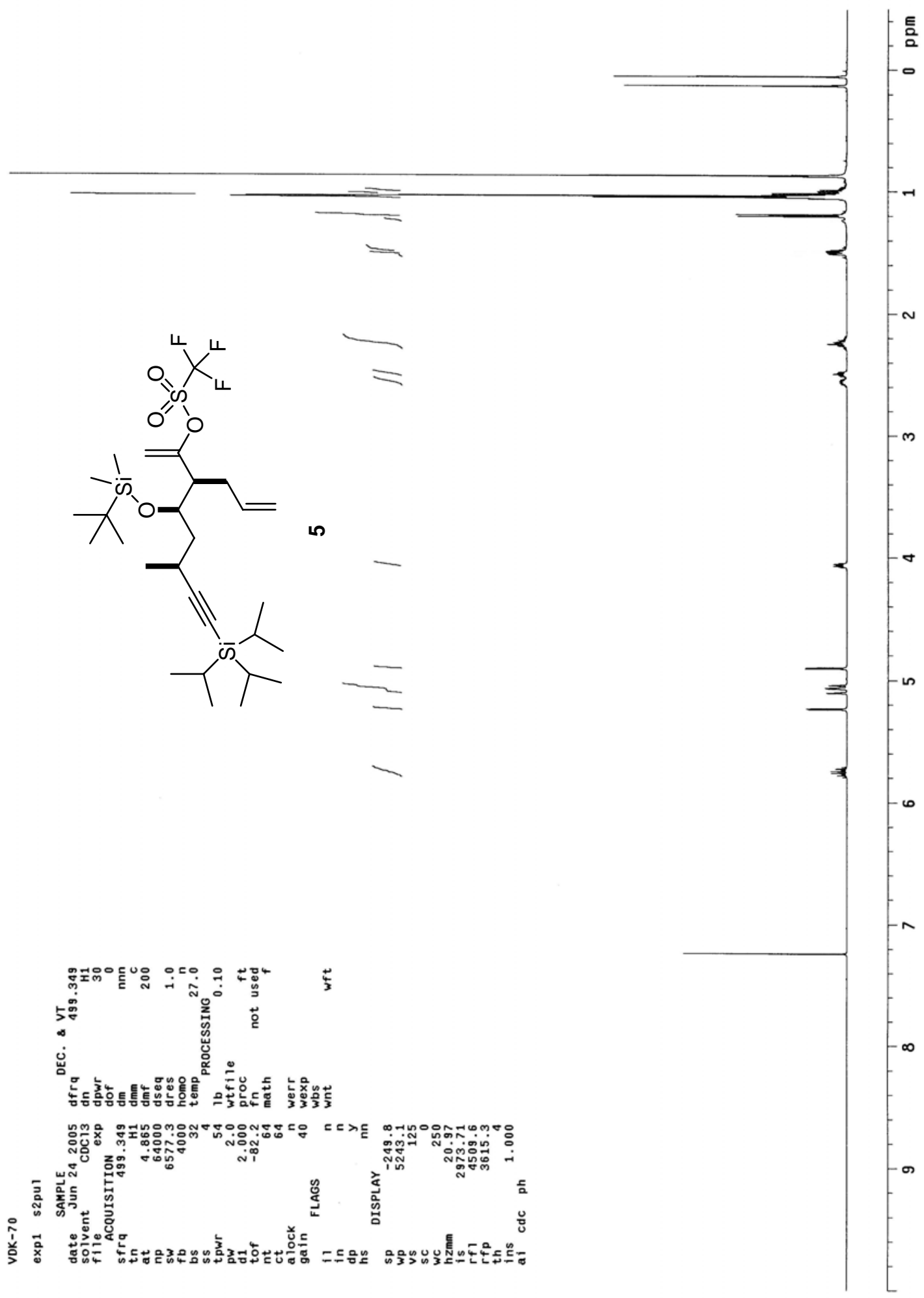




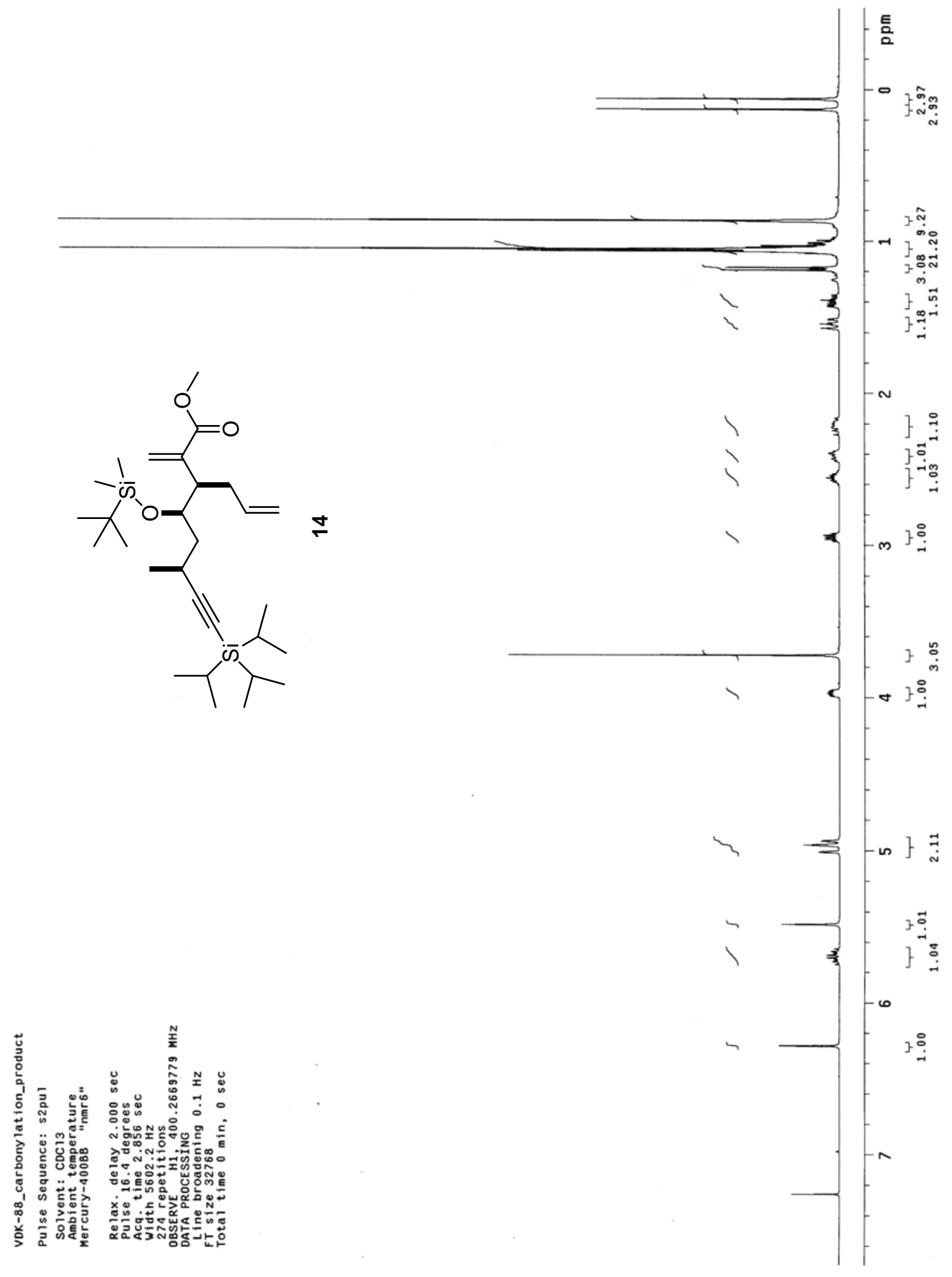




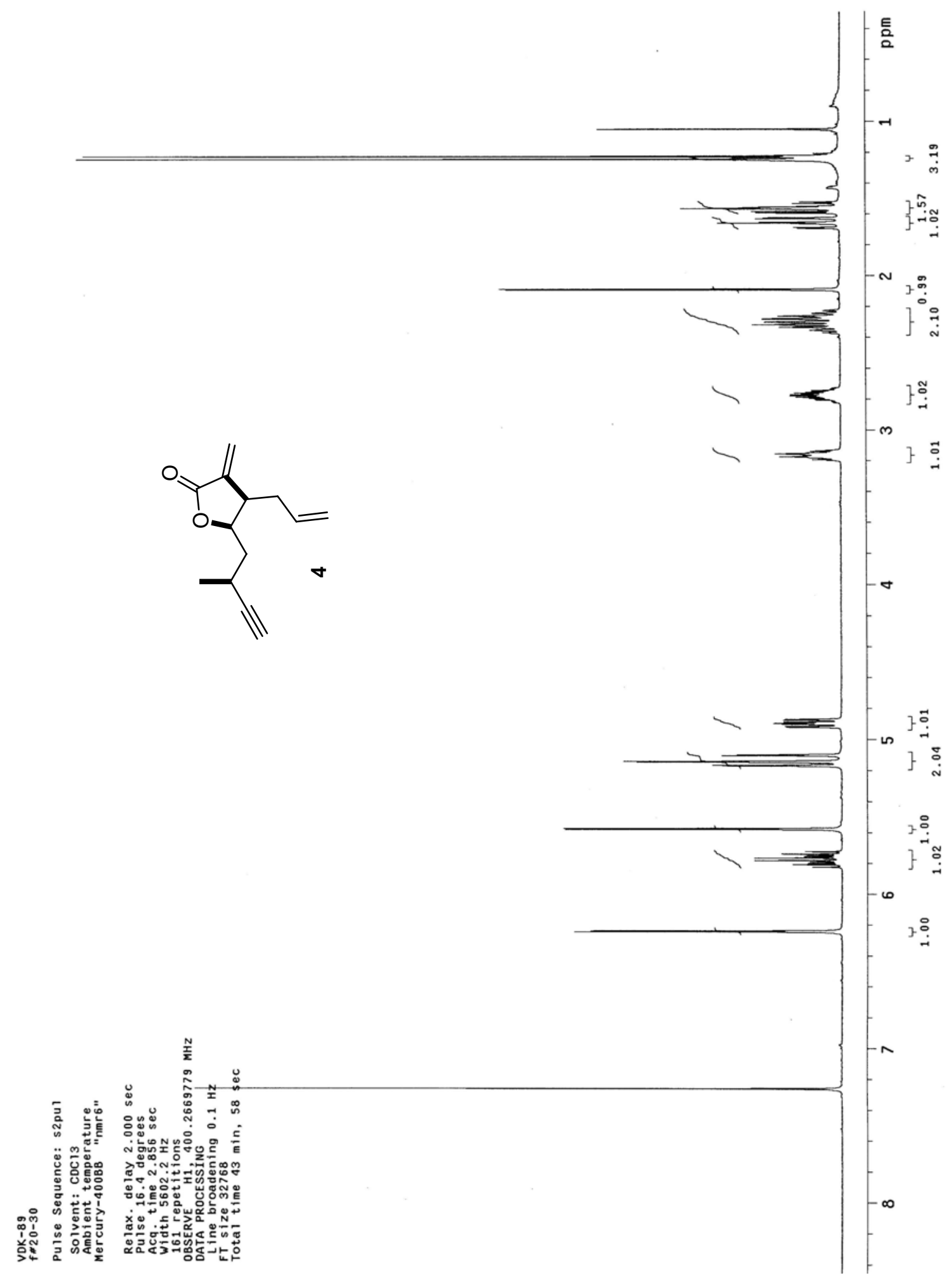



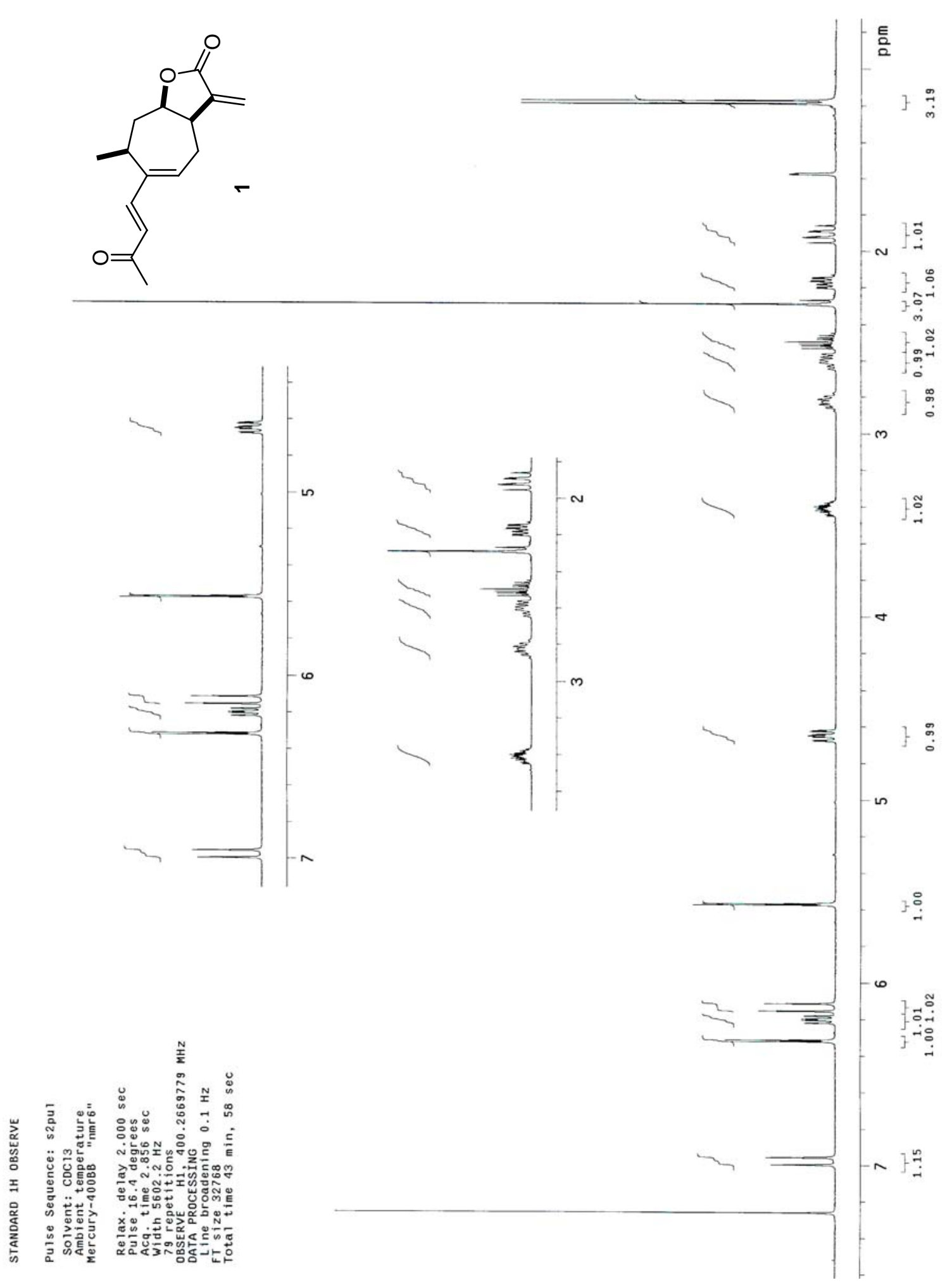


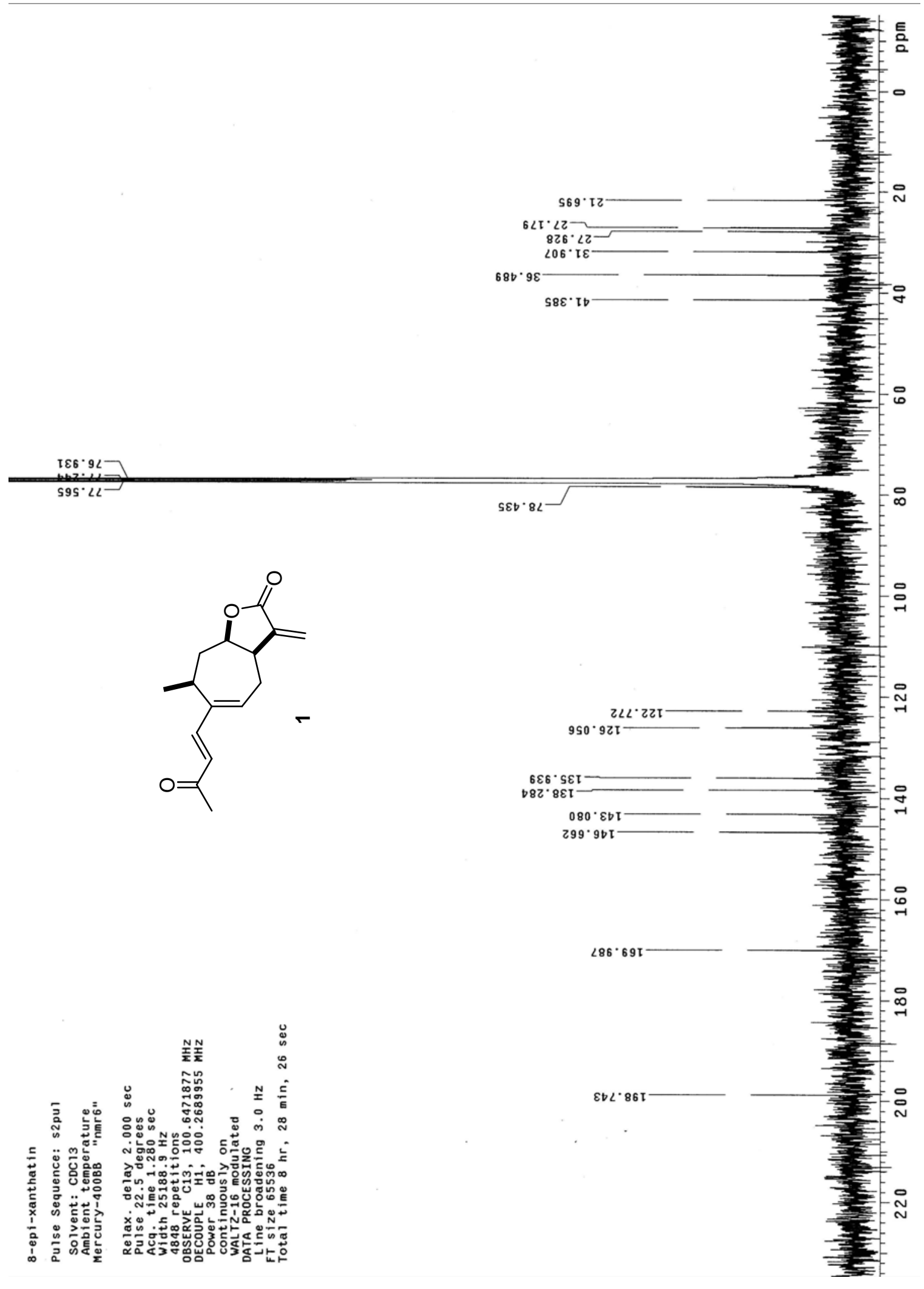

